\title{
Conflictos de narrativas sobre el pasado en los márgenes de la Argentina: el Chaco en la primera mitad del siglo $\mathrm{XX}^{1}$
}

\section{Conflicts of narratives about the past on the margins of Argentina: Chaco in the first half of the 20th century}

María Silvia Leoni ${ }^{2}$

Resumen:

Nos proponemos analizar cómo se fueron definiendo distintas y a veces contrapuestas representaciones del pasado chaqueño dentro de un espacio intelectual en formación durante la primera mitad del siglo $\mathrm{XX}$. Al atender al papel de la historiografía, en su sentido amplio, para la construcción de las identidades regionales/provinciales, se pueden establecer las particulares prácticas de integración cultural a la nación que se realizaron desde este espacio. Las tres líneas interpretativas identificadas, con sus respectivos representantes, producciones y lugares de memoria instituidos, entraron en debates que enmarcarían la emergencia de una historiografía profesional en la segunda mitad del siglo.

Palabras clave: historiografía; campo intelectual; representaciones del pasado; territorios nacionales; Chaco

\begin{abstract}
:
This article analyzes how different and sometimes conflicting representations of the Chaco past were defined within an intellectual space in formation during the first half of the 20th century. By attending to the role of historiography, in its broad sense, for the construction of regional / provincial identities, can be established the particular practices of cultural integration to the nation that were carried out from this space. The three interpretive lines identified, with their respective representatives, productions and places of memory, entered into debates that would frame the emergence of a professional historiography in the second half of the century.
\end{abstract}

Keywords: historiography; intellectual field; representations of the past; national territories; Chaco

${ }^{1}$ Trabajo recibido el 07/09/2020. Aceptado el 27/10/2020.

${ }^{2}$ Universidad Nacional del Nordeste. Contacto: mariasilvialeoni@hotmail.com 


\section{Introducción}

Hace más de una década, Alejandro Cattaruzza (2003) mapeaba el campo de la historia de la historiografía y advertía que, además del análisis de la producción historiográfica, aquella buscaba «desplegarse sobre frentes múltiples: las condiciones de producción y la constitución del discurso acerca del pasado; la relación entre los productos de la historia profesional y el mercado de bienes culturales, la organización de lugares de la memoria colectiva', los aspectos institucionales que impactan en la producción historiográfica y las conexiones que esas particulares instituciones sostienen con los demás sectores del mundo cultural y científico» (p.204). Esta ampliación del campo en las últimas décadas ha dirigido la atención a cuestiones tales como las culturas históricas, ${ }^{3}$ los regímenes de historicidad, los procesos identitarios, es decir, las distintas formas de articulación de las sociedades con su pasado.

Entre otros, se destacan los enfoques que atienden a las maneras en que los poderes establecidos se fundan a partir de la recreación de un pasado postulado como compartido. Así, se procura desentrañar el sentido que las elites le han dado al pasado para apuntalar sus construcciones sociales y las estrategias empleadas para imponer determinadas interpretaciones ante los conflictos de memorias circulantes.

Si bien existe una importante producción sobre el papel de la historiografía en la construcción de los imaginarios nacionales, más recientemente se comenzó a atender a la función que ha cumplido en la definición de los imaginarios regionales y provinciales. En este sentido, resultan de interés los trabajos historiográficos desarrollados por autores españoles, colombianos, mexicanos y brasileños. Para Forcadell (2006), el «provincialismo» constituye un campo de análisis de incumbencia de la historia de las culturas políticas, la historia sociocultural y la historia de las identidades y su abordaje es una manera de reflexionar sobre el papel de la memoria en la configuración de proyectos políticos y de estos en la imaginación de identidades. De estas manera, se han podido establecer las particulares prácticas de integración cultural a la nación que se realizaron desde los distintos espacios y, como veremos aquí particularmente, desde el espacio chaqueño.

\footnotetext{
${ }^{3}$ La noción de cultura histórica de Jorn Rusen (1994) contempla las diferentes estrategias de la investigación científico-académica, de la creación artística, de la lucha política por el poder, de la educación escolar y extraescolar, del ocio y de otros procedimientos de memoria histórica pública, como concreciones y expresiones de una única potencia mental.
} 
Los intelectuales/notables/hombres de ideas/productores culturales -según como se opte por denominarlos- de provincia de las primeras décadas del siglo XX, que «aprovechaban las ambigüedades de un capital inespecífico» y que hoy «siguen teniendo correlatos en estos bordes de la producción científica en humanidades y ciencias sociales» (Martínez, 2013, p.176), han jugado un papel determinante en la tarea simbólica de construcción de los regionalismos y provincialismos, apelando, entre otras herramientas, a la historia.

En Argentina, los estudios sobre la construcción de identidades regionales se han desarrollado fundamentalmente atendiendo a los conocimientos geográficos que se generaron para sustentarlas (Benedetti, 2009) o al papel de los intelectuales locales (Laguarda y Fiorucci, 2012; Martínez, 2019). Más escasos han sido los abordajes relativos al vínculo de los estudios históricos con las construcciones identitarias provinciales y regionales, entre los que podemos mencionar algunos trabajos sobre las regiones Noroeste -incluidos en los trabajos arriba citados-, Nordeste (Leoni, 2015) o sobre provincias como Córdoba (Philp, 2011 y 2013), Santa Fe (Micheletti, 2017) o Misiones (Jacquet, 1996).

En esta oportunidad, buscamos identificar las distintas y a veces contrapuestas representaciones del pasado local que se generaron dentro de un espacio intelectual chaqueño en formación. Ellas enmarcarían la emergencia de una historiografía profesional en la Facultad de Humanidades de la Universidad Nacional del Nordeste, en ineludible diálogo con dichas representaciones. Este contexto permite explicar las agendas de la novel historiografía profesional, relación que no ha sido atendida aún.

\section{Construir historias para territorios sin pasado}

La preocupación por la historia de la zona chaqueña fue escasa por largo tiempo en el ámbito nacional. Los primeros aportes al conocimiento geográfico, antropológico e histórico de la región, que datan del período colonial, provinieron de los religiosos que se introdujeron para evangelizar y de los conquistadores que cruzaron el territorio en busca de rutas alternativas.

Los espacios que se organizaron como territorios nacionales en el nordeste argentino a fines del siglo XIX -Formosa, Chaco y Misionestuvieron un desarrollo historiográfico tardío e inicialmente subsidiario 
de la historiografía correntina, debido a las características de su particular organización institucional.

Las representaciones elaboradas entonces sobre dichos espacios provinieron de los discursos de funcionarios del gobierno nacional y de integrantes de instituciones geográficas vinculadas, como el Instituto Geográfico Argentino y la Sociedad Geográfica Argentina, involucrados en las prácticas de apropiación material del Chaco. Estas sociedades publicaron revistas y boletines, en los cuales los relatos de expediciones y campañas al Chaco fueron uno de los tópicos recurrentes y más extensamente abordados (Lois y Troncoso, 1998). Sus trabajos sostenían la imagen del Chaco como un «desierto verde», un vasto espacio sin pasado. Al ser un área «vacía», le correspondió a la geografía volverla objeto de conocimiento y ocupar así un lugar privilegiado en la formación de una conciencia territorial nacional (Davilo y Gotta, 2000).

Finalizada la conquista e iniciado exitosamente el proceso de incorporación al sistema nacional dentro del modelo de economía primaria exportadora, a través de la explotación del quebracho primero y del cultivo del algodón, después, se planteó la necesidad de brindar una imagen del Chaco basada en los relatos de la apropiación por parte del estado nacional y que al mismo tiempo demostrara los avances logrados por los nuevos habitantes en tan pocos años.

Esta tarea quedó en manos de quienes habían participado activamente en el proceso evangelizador en la Argentina moderna, como es el caso de las Memorias del prefecto de misiones fray Rafael Gobelli OFM (1912-1916), o en el de ocupación del espacio, como Manuel Obligado, ${ }^{4}$ con La conquista del Chaco austral: contribución a la historia (1925).

Tendrían continuidad también a través de los descendientes de estas figuras, como en el caso de Ricardo Foster, ${ }^{5}$ hijo de Enrique Foster, agrimensor de la colonia Resistencia, quien publicó su Contribución a la

\footnotetext{
${ }^{4}$ M. Obligado (1838-1896). Estuvo al mando de la frontera interior chaqueña (1870) donde tuvo un papel destacado; $y$ fue designado primer gobernador del Territorio Nacional del Chaco (1884-1887). La Casa de gobierno provincial cuenta con el «Salón Obligado» y el «sillón de Obligado».

${ }^{5}$ Foster, R. (1881-1962). Conservador, doctor en ciencias jurídicas, diputado provincial por Santa Fe (1934-1935) y ministro de instrucción pública de la misma provincia (19361937). Docente secundario y universitario, fue decano de la Facultad de Derecho de la Universidad Nacional del Litoral en dos oportunidades y vicerrector de la Universidad (1928-1929).
} 
historia del Chaco (Exploración de 1875-1876 y fundación de Resistencia) (1939), texto de una conferencia que diera en 1937 en Resistencia, auspiciada por la Sociedad Científica Argentina. Foster aboga por escribir una historia del desarrollo de las distintas comarcas del país «y la actuación de quienes fueron los meritorios ciudadanos, militares o civiles, que no obstante haberse esforzado por fortalecer la patria... aún permanecen en el anonimato». Este era un imperativo para «todo verdadero argentino» que, por su parte, cumple al rescatar la gesta paterna, un hito en la incorporación del Chaco a la nación:

Es la voz de la sangre que difícilmente puede acallarse... de un modesto agrimensor que con pujanza y decisión, cimentadas en un ideal eminentemente patriótico, abría surcos imborrables y plantaba en ellos la semilla que con el andar de los tiempos habría de convertirse en la lozana planta que es hoy exponente del progreso alcanzado por las argentinas comarcas del Chaco (p. 18).

Foster realiza una propuesta de periodización en la que determina tres épocas: de la colonización jesuítica (1660-1767), que constituiría un antecedente de la ocupación por parte de la nación; de los obrajeros blancos (1767-1875), que marcaría un momento preparatorio para la época principal: la de la colonización argentina (desde 1875 en adelante). En los orígenes de Resistencia rescata, en primer lugar, a los obrajeros correntinos, esforzados «pioneers» del desierto verde de la Argentina», dejando de lado la consideración del papel del inmigrante, en su esfuerzo por remarcar la argentinidad de estos acontecimientos inaugurales. Si bien admite que estuvieron guiados ante todo por la codicia de las ricas maderas que explotaban», rescata su decisión, voluntad y coraje «para exponer la vida a cada instante en un medio ambiente adusto y bravío como el del Chaco de entonces».

Aquí encontramos todos los tópicos que caracterizarían a los discursos oficiales sobre el Chaco: el «desierto verde»; el territorio salvaje conquistado con bravura por los argentinos; el papel central de los pioneros que hicieron patria para incorporarlo a la «civilización».

Desde el gobierno nacional se encaró la institución de lugares de memoria en los territorios nacionales a través de la Comisión Nacional de Museos y Monumentos y Lugares Históricos, creada en 1938. En contraste con las provincias, los territorios nacionales aparecieron con una memoria diferencial caracterizada por la escasez de recordatorios. 
Estos, en su mayoría mencionaban dos campañas colonizadoras: las fundaciones frustradas de la empresa española y las campañas militares y evangélicas del siglo XIX (Masotta, 2001) que, como veremos, enlazarán con algunas de las interpretaciones que se construirían localmente entonces.

La otra herramienta central utilizada para la construcción de una identidad argentina fue la enseñanza de la historia nacional en las escuelas, con el objetivo de nacionalizar a los habitantes y despertar sentimientos patrióticos. Esta historia, que integraba a los territorios nacionales al devenir de la nación, gracias a la acción del estado y sus agentes, se transmitía en el aula y a través de las conmemoraciones patrias, que a veces entraron en conflicto con las propias de los grupos inmigrantes.

\section{Un protoespacio historiográfico: el campo intelectual chaqueño}

Organizado e iniciado el desarrollo económico del Territorio, a principios del siglo XX se manifestó en él la necesidad de disponer de alguna forma de saber organizado en torno a los orígenes, las características y el sentido de su desarrollo, sus rasgos distintivos, sus logros y fracasos.

Las características del poblamiento del Chaco determinaron la heterogeneidad y movilidad de su sociedad. ${ }^{6}$ No hubo una elite con fuerte tradición histórica; el proceso de elitización se produjo fundamentalmente a través del éxito económico: los migrantes exitosos se sumarían a integrantes de la elite correntina con vinculaciones en el territorio, profesionales y altos funcionarios públicos llegados con cada nueva gestión, representantes de las grandes empresas radicadas en el Chaco y a un reducido grupo intelectual, conformado por los dueños de periódicos, directores de escuelas y algunos profesores de los escasos colegios secundarios existentes. Esta elite se vinculó a través de instituciones étnicas, económicas, sociales, culturales y recreativas que fueron surgiendo en las primeras décadas del siglo XX.

\footnotetext{
${ }^{6}$ Para mediados del siglo XX, más del 90\% de los habitantes del Chaco eran argentinos, pero sólo un $56 \%$ había nacido en la jurisdicción. Estas cifras indican que, ya para entonces, la calidad de «tierra de inmigrantes» era más una consecuencia de la convergencia hacia el Chaco de migrantes de otras provincias argentinas que de europeos, aunque la imagen de «crisol de razas» perduraría a través del tiempo.
} 
La política municipal fue el único ámbito de participación directa con que contaron los habitantes de los territorios nacionales, por lo que los municipios eran considerados «escuelas de gobierno propio». Así, la constitución del ciudadano se produjo en el ámbito municipal: para la década de 1930, existían en el Chaco diez municipios, cuyo gobierno disputaban radicales, socialistas y distintas agrupaciones vecinales surgidas circunstancialmente.

Algunos integrantes de la dirigencia local se organizaron en agrupaciones, movimientos y congresos para solicitar al gobierno nacional la ampliación de los derechos políticos y mejoras en las condiciones judiciales, educativas, sanitarias y de infraestructura del territorio. Esta dirigencia asumió un rol de intermediaria entre el conjunto de la sociedad y el estado, así como de formadora de la identidad territoriana.

En el Chaco no hubo instituciones ni historiadores profesionales hasta la década de 1960, anteriormente escribieron historia periodistas, maestros, naturalistas, sacerdotes, que la consideraron una actividad complementaria de su labor intelectual.

El periodismo se constituyó en vocero de este sector. El aporte de los periódicos locales a la labor historiográfica fue significativo: se publicaron trabajos, si bien inorgánicos, dispersos, que no dieron lugar a un saber sistemático, contribuyeron a formar el sentido de pertenencia, crear interés, ilustrar acerca de sucesos y personajes, preparando el camino para el desarrollo historiográfico. Aparecieron artículos sobre el pasado reciente que buscaban rescatar personajes o hechos considerados significativos, en los cuales prevaleció la transcripción de testimonios orales de primeros pobladores y sus descendientes; se recordaron los aniversarios de la fundación de ciudades y pueblos, muchas veces a través de artículos que reflejaban su nacimiento y desarrollo.

Las polémicas en torno al pasado también se desarrollaron a través de los periódicos. Estas discusiones, insertas en las búsquedas de la identidad chaqueña, se dirigían a la identificación de sus raíces, para así también legitimar a determinados grupos sociales. La revista Estampa Chaqueña, en 1929 daría cabida en sus páginas, entre otros, al debate en torno al gentilicio que debían adoptar los habitantes de Resistencia, con la intervención de dos de los notables más reconocidos: Enrique Lynch Arribálzaga ${ }^{7}$ remontaba los primeros gentilicios a 1916, para rechazarlos

\footnotetext{
${ }^{7}$ E. Lynch Arribálzaga (Buenos Aires, 1856-Resistencia, 1935), naturalista, participó de expediciones al Chaco hasta que se estableció allí en 1907, como delegado regional de
} 
(resistense, resistenceño, resistenciero, resistenciano), por no ser «agradables al oído»y proponer «fernandinos». Para ello recurría a fundamentos históricos, ya que la ciudad se había ubicado en la zona donde estuviera anteriormente la reducción de San Fernando del Río Negro. Nicolás Rojas Acosta, por su parte, rechazaba esta propuesta y defendía el gentilicio «resistenciano», que finalmente se impuso. ${ }^{8}$

La necesidad de constituir un campo intelectual fue señalada en numerosas oportunidades por estos actores. Lynch Arribalzaga se proponía entusiasmar a los jóvenes territorianos para el estudio de la historia local y la investigación científica con sus Materiales para una bibliografía del Chaco y de Formosa (1924). Alentaba a que este núcleo intelectual se generara a partir de los jóvenes formados en la Escuela Normal de Resistencia, en las universidades y los institutos de Corrientes, Buenos Aires y La Plata. Encontró el modelo a seguir en la Asunción colonial y «aquel culto Ruy Díaz de Guzmán que, nacido y criado en la época semibárbara de la conquista y la colonización primera del Río de la Plata, en un rincón del Paraguay, supo con todo acopiar noticias y ordenarlas, para redactar la primera historia de estos países que haya sido escrita»(p. 5)

Los gobiernos territorianos, designados desde Buenos Aires, no se ocuparon de promover las actividades historiográficas ni de proporcionar las condiciones institucionales para su desarrollo. Podemos citar dos intentos realizados desde esferas oficiales locales en este sentido.

El primero de ellos surgió desde el ámbito de la municipalidad de Resistencia. Lynch Arribálzaga, como secretario municipal, creó el primer Museo del Territorio, conjuntamente con la Biblioteca Municipal, que funcionaron entre 1923 y 1925. El objeto de la primera institución era «reunir, exhibir y estudiar materiales y documentos sobre la historia, la geografía, la bibliografía, la fauna, la flora, la etnografía, la agricultura y la industria del Chaco, en general, y de Resistencia, en particular». ${ }^{9}$ Los trabajos a que dieran lugar estas investigaciones se publicarían en el Boletín

Defensa Agrícola. Publicó numerosos trabajos sobre problemáticas políticas, sociales y económicas en diarios y revistas de Buenos Aires, La Plata y Chile. Fundó y dirigió la reducción de Napalpí, fue director del periódico chaqueño El Colono (1920-1922) y comisionado municipal de Resistencia (1931). Encabezó distintos movimientos en favor de los derechos políticos de los chaqueños.

${ }^{8}$ Nuestro gentilicio. Estampa Chaqueña, No 6, 8-XI-1929, p.1; No 11, 13-XII-1929, p.p. 5 y 7.

${ }^{9}$ Archivo Municipal. Digesto Municipal. Decreto del Concejo Municipal, 8-VII-1923. 
Municipal. Lynch Arribálzaga advertía que si bien no se hallaría allí la historia del Chaco, si se encontrarían los materiales para elaborarla. Asimismo, establecía las reglas: «expondremos imparcialmente los hechos; el lector juzgará, de acuerdo con sus ideas». ${ }^{10}$ Lynch se propuso convertir al Boletín en una revista con alcance internacional, por lo cual inició el intercambio con centros universitarios y científicos de Buenos Aires. Sin embargo, el conflictivo desarrollo de la política municipal lo obligó a alejarse del cargo, con lo que finalizó este emprendimiento.

Otra iniciativa se debió, una década después, al gobernador del territorio José Castells, porteño, quien en 1937 creó el Museo Histórico del Chaco, al que colocó bajo una dirección compartida por el secretario de la Gobernación, el jefe del Distrito Militar, el secretario de la Vicaría Eclesiástica, el director de la Escuela Normal, el inspector de la Seccional de Escuelas y el presidente de la Sociedad de Estudios Científicos del Chaco. El guión del Museo debía consignar las distintas etapas civilizadoras por las que pasó el Chaco, con una población que se formó «casi exclusivamente por aporte inmigratorio, más que por población autóctona» ${ }^{11}$. El Museo debía tener un pabellón destinado a mostrar el progreso algodonero del Chaco.

Castells reconocía el interés creciente en los círculos intelectuales por la historia del territorio, interés que el gobierno debía estimular «como factor indispensable para el afianzamiento de la nacionalidad», lo cual se lograría «sobre bases más reales y metódicas». Esta propuesta, criticada desde las páginas del diario El Territorio por la conformación y orientación del Museo, no llegó a concretarse. ${ }^{12}$

Ya provincializado el Chaco, se crearía en 1954, bajo el gobierno de Felipe Gallardo, el Archivo, Biblioteca y Museo Histórico de la Provincia. Al frente de esta institución, se colocó a Monseñor José Alumni. Las secciones de biblioteca y de museo no llegaron a organizarse, pero el Archivo, con vaivenes, tuvo continuidad hasta el presente.

Mientras vemos aparecer Juntas de Historia en provincias desde la década de 1920 y fundamentalmente en la de 1930, en el Chaco no haría su aparición hasta la década de 1970, cuando la carrera de Historia ya se hallaba en funcionamiento en la Universidad. Se marcaría una diferencia con el territorio de Misiones, que tuvo su Junta en la década de 1940.

${ }^{10}$ Boletín Municipal. Resistencia, $\mathrm{N}^{\circ} \mathrm{1}, 1924$.

${ }_{11}$ Transcripto en El Territorio, Resistencia, 9-XII-1937, p.3.

${ }^{12}$ Ibid. 


\section{Perspectivas en conflicto para la historia del Chaco}

En la primera mitad del siglo XX se desarrollaron tres perspectivas sobre el pasado chaqueño, que rescataron distintos momentos, grupos y marcadores identitarios, por lo que entrarían en conflicto. Cada una de ellas tuvo sus referentes y construyó sus lugares de memoria. Podemos definirlas como las perspectivas inmigratoria, correntina y católica.

A partir de la década de 1920 se define y busca imponerse la interpretación de los descendientes de los inmigrantes italianos que arribaron para poblar Resistencia en 1878. Estuvieron representados por Juan Ramón Lestani, ${ }^{13}$ esforzado por construir una identidad chaqueña en la cual el «otro» era Corrientes, percibida, en contraposición con el Chaco, como una sociedad tradicionalista, atrapada por su pasado, ajena al espíritu del inmigrante y que había extendido una nociva tutela política y cultural sobre el territorio chaqueño.

Si bien inicialmente la conmemoración del arribo de los inmigrantes, fijada en el 2 de febrero, quedó restringida a los descendientes, luego se buscó imponerla en el conjunto de la sociedad chaqueña, transformándola en el acto fundacional de la ciudad pero, a pesar de los esfuerzos, sin lograr el consenso necesario como para convertirla en el acto inaugural de la historia del territorio. No obstante, el 2 de febrero se identificó definitivamente como la fecha de nacimiento de la ciudad de Resistencia. Sus lugares de memoria serían el monumento a la Loba romana en la plaza central y el monolito con los nombres de las primeras familias italianas.

Esta línea interpretativa sería incorporada por el socialismo chaqueño y se manifestaría en la obra histórica Tres ciclos chaqueños (1955) de Guido Miranda, considerada la producción más importante de la historiografía chaqueña. También sustentaría el proyecto presentado por los representantes de ese partido a la Convención Constituyente Provincial reunida en 1957.

Por su parte, los dos historiadores correntinos más importantes, Manuel F. Mantilla y Hernán Gómez, abordaron inicialmente el pasado chaqueño en tanto se vinculaba con la historia de su propia provincia,

\footnotetext{
${ }^{13}$ J.R. Lestani (Resistencia, 1904-1953) pertenecía a la tercera generación de una de las familias italianas que desembarcaron en 1878. Político socialista, fue el primer intendente nativo de Resistencia, entre 1933-1935 y 1940-1942. Se dedicó al periodismo político y participó en la gestación de varios movimientos por los derechos políticos de los territorianos.
} 
resaltando el papel central que ella había jugado en la ocupación de ese espacio. En 1919, el periódico Heraldo del Chaco reproducía un trabajo de Mantilla sobre la fundación de San Fernando del Río Negro que formaba parte de su Crónica histórica de la provincia de Corrientes, obra que fuera publicada completa recién en 1928.

Hernán Gómez también se encargó de elaborar el primer manual de historia local, destinado a las escuelas. En su Historia de la Gobernación del Chaco (1939) señalaba la importancia del conocimiento del pasado para que los futuros ciudadanos del Chaco se identificaran en la proyección de un pasado argentino común. En su obra destaca una historia de siglos, en la cual «es siempre mayoría la estirpe de la provincia limítrofe de Corrientes, cuya emigración forma el protoplasma fecundo de tanta maravilla» (p. 8) . Al remarcar el papel de Corrientes en el desarrollo del Chaco, el arribo de los inmigrantes europeos cumple un papel secundario.

Si bien este fue el único texto con que contaron por varios años los escolares chaqueños para conocer su historia, queda por determinar la circulación y recepción del mismo por parte de docentes y alumnos para poder establecer su impacto en la construcción de una determinada imagen del pasado chaqueño. Aunque debe destacarse el papel central de los docentes correntinos en las principales escuelas y colegios de Resistencia, como lo denunciara J.R. Lestani.

La determinación de los orígenes de la ciudad de Resistencia, como se ha señalado, considerada fundamental por constituir el punto de inflexión en el proceso de incorporación del Chaco al estado nacional, recibiría la atención de la perspectiva correntina. El intendente de Resistencia, Eduardo Miranda Gallino (correntino), advertía en 1928 la necesidad de evitar interpretaciones equívocas, por lo cual encargó a Lynch Arribálzaga la compilación de los antecedentes de la fundación de Resistencia. ${ }^{14}$ Los resultados de esta tarea, publicados en el Boletín Municipal, permitían identificar a los primeros pobladores: un grupo de obrajeros correntinos, por lo que se advertía que «según curiosos criterios históricos, a muchos se les quiere asignar el título hermoso de fundadores, pero a ninguno de ellos les corresponde en realidad» (Lynch Arribalzaga, 1972 , p. 47), en clara referencia a la gesta de los inmigrantes europeos.

En la década de 1930, la preocupación por esta interpretación se manifestaría muy fuertemente. Así, desde el periódico El Territorio se

${ }^{14}$ La Voz del Chaco, $1^{\circ}-$ II-1928, p.5. 
denunciaba que el gobernador de Corrientes había dirigido un documento a la Comisión de Límites Interprovinciales solicitando que se le entregaran las islas del Paraná que estaban bajo jurisdicción del Chaco, con el fundamento de que Corrientes había fundado Resistencia.

En la década de 1940 se define una tercera línea interpretativa. En consonancia con las corrientes que se desarrollaban a nivel nacional, se realizará el esfuerzo por rescatar las raíces católicas e hispánicas de la cultura chaqueña. Los trabajos arqueológicos, la producción historiográfica y la conmemoración, en 1950, del bicentenario de la reducción de San Fernando del Río Negro, son algunos de los indicadores.

La Iglesia católica se había insertado en el espacio chaqueño desde mediados de la década de 1930, con la creación de la Vicaría Eclesiástica para Chaco y Formosa. A cargo de ella quedó Monseñor Nicolás De Carlo, luego primer obispo de la diócesis de Resistencia (1940-1951), quien imprimió gran dinamismo a las actividades de la Iglesia, acompañado por el presbítero José Alumni. ${ }^{15}$ De Carlo establecería un importante vínculo con el presidente Juan D. Perón, a través del apoyo a la obra social del obispo, quien a su vez respaldó el proceso de provincialización.

Bajo el impulso de Alumni, en la década de 1940 se iniciaron los trabajos arqueológicos en el Chaco, que se concentraron en la búsqueda de sitios hispánicos, para lo que contó con la colaboración de Alfredo Martinet, industrial de la ciudad de Presidencia Roque Sáenz Peña. En 1942 encontraron las ruinas del $\mathrm{Km} 75$, atribuidas a la ciudad hispánica de Concepción del Bermejo y, al año siguiente, las de Pampa Tolosa. Paralelamente, la Comisión Nacional declaró lugares históricos en el Chaco a los sitios de la Reducción de Nuestra Señora de Dolores y Santiago de Mocobí o La Cangayé (sin localizar en ese momento); de la Reducción de San Bernardo de Vértiz y de la ciudad de Nuestra Señora de la Concepción del Bermejo y Timbó.

Alumni ubicó el sitio de La Cangayé en 1946. Ante el hallazgo, se organizó una excursión desde Resistencia a las ruinas y un acto conmemorativo seguido de una misa en el lugar, encabezados por las autoridades del territorio. Para Alumni, el Chaco recibió alborozado los hallazgos debidos al esfuerzo privado que debían constituirse en

15 J. Alumni nació en Cortona (Italia) y falleció en Buenos Aires (1907-1963). Radicado en el Chaco entre 1936 y 1956, fue Secretario de la Vicaría Eclesiástica y Vicario de la Diócesis en Sede Vacante (1951-1955). 
«monumentos venerados de nuestro pasado». Reclamaba entonces el apoyo gubernamental para continuar la tarea de búsqueda y preservación (Alumni, 1948, p.65).

De Carlo incentivó la labor historiográfica de Alumni para atacar «la utopía de querer comenzar la historia del Chaco en un cercano ayer... adulterando o encubriendo los hechos», cuando en el pasado hispánico se hallaban las raíces de la identidad chaqueña que «tiene raíz y savia cristiana; sus páginas están escritas con sangre de mártires y con sacrificios sin número de misioneros» (Alumni, 1951, p. XV).

Para Alumni, la idea de un Chaco sin pasado se debió a la existencia de un presente extraordinariamente dinámico y pujante que impedía «la clara percepción de un pasado de gloria y de sacrificio», así como de su influencia sobre ese presente. Se esforzará entonces por demostrar dicha continuidad a través del «lazo místico del glorioso San Fernando». La continuidad de la tradición católica se había logrado a través de los obrajeros correntinos:

La humilde y primitiva Iglesia, baluarte contra la barbarie y primer faro que derramó sus luces de verdad y progreso en esta vasta región de la patria, se ha transformado en centro de un nuevo progreso cuya pujanza solo sueña un porvenir de victorias. (Alumni, 1951, p.127)

En agosto de 1950, De Carlo y Alumni, con apoyo gubernamental, instituyeron la conmemoración del bicentenario de la reducción de San Fernando del Río Negro, en contraposición a la del 2 de febrero. Se organizó una semana de festejos que incluyeron la inauguración de un monolito, actos públicos y conferencias, con la participación del ministro de Educación de la Nación y de Guillermo Furlong, principal referente de Alumni. Exaltado con la repercusión obtenida, afirmaba Alumni que había llegado para el pasado del Chaco la hora de la justicia y de la reivindicación (Alumni, 1951).

Instituidas las dos fechas, en 1965, Seferino Geraldi, otra figura destacada del campo cultural chaqueño y descendiente de los inmigrantes friulanos, recriminaba que se hubiera intentado hacer aparecer a Resistencia como fundada en 1750 «y en muchos aspectos lo lograron, puesto que gente mal informada todavía sigue sosteniéndolo» (Geraldi, 1965 , p. 209). Las dos fechas quedarían finalmente oficialmente establecidas. 


\section{Hacia el surgimiento de los estudios históricos universitarios}

Las tres líneas interpretativas identificadas se encontraban vigentes al momento de creación de la Universidad Nacional del Nordeste en 1957. A su vez, serían tensionadas por un nuevo debate que se planteó entonces, debido a los procesos de regionalización de la Argentina. La definición de una región Nordeste llevaría a revisar la construcción de un pasado de la región chaqueña -que las tres reconocían- para plantear las posibilidades de una historia nordestina, que hemos analizado en otra oportunidad. Los profesores de historia que arribarán a Resistencia de Buenos Aires y Entre Ríos para encarar la organización de los estudios universitarios desarrollaron sus planes y sus investigaciones en este contexto.

Por último, agregamos que en las representaciones analizadas, los pueblos indígenas o bien son considerados parte del paisaje y de los peligros que debieron enfrentar los conquistadores y evangelizadores, una rémora de la civilización, o bien se incorpora una visión romantizada donde se rescata su férrea defensa del terruño, pero no se les otorga un lugar en la construcción identitaria. Variados trabajos han analizado, desde la antropología, las representaciones construidas sobre el indígena chaqueño y las transformaciones que sufrieran a lo largo del siglo XX. Pero si atendemos a la construcción de los discursos históricos, advertimos su invisibilización en ellos hasta la década de 1960, momento en el que también se manifiesta el interés por los pueblos indígenas en la antropología profesional.

Ramón de las Mercedes Tissera -al margen de la academia- abogó por su integración a la «invertebrada historia del Chaco» y retomaría la polémica sobre los orígenes, reconociendo las consecuencias negativas que esta visión tenía para la formación de las nuevas generaciones: «No alarma mayormente el contenido mesiánico que se le asigna al 2 de febrero de 1878 sino la subestimación que lleva implícita respecto a las demás corrientes propulsoras del Chaco moderno» (Tissera, 1972, p. 48).

A partir de esta caracterización de las líneas interpretativas, queda por establecer los diálogos que establecieron con la historia profesional y cómo impactaron en ella, para una mejor comprensión del particular desarrollo de la historiografía chaqueña. 


\section{Reflexiones finales}

Si bien la producción historiográfica chaqueña tuvo un escaso desarrollo hasta las últimas décadas del siglo XX, la creciente preocupación por la definición de la identidad chaqueña despertó el interés por la historia en el espacio intelectual que se fue construyendo a principios de siglo, el cual no se encontró con un folklore en el cual abrevar ni un devenir de la «civilización» de larga prosapia.

Inicialmente, la atención se centró en los orígenes de las ciudades y pueblos, lo que permitió dar una filiación a determinados grupos para que jerarquizaran su ubicación en la estructura social. En el caso de Resistencia, la resolución de esta cuestión sería más acuciante, ya que la discrepancia en torno al lugar de este acontecimiento en la historia del Chaco y quienes fueron sus «verdaderos» protagonistas, permitía dirimir fundamentalmente el lugar que correspondía a correntinos e inmigrantes europeos como actores principales del «hacer Chaco».

El desarrollo de los trabajos arqueológicos contribuyó, a partir de la década de 1940, a rescatar el pasado hispánico y católico, hasta entonces poco conocido y considerado, en una perspectiva que no se contradecía mayormente con la correntina.

Los historiadores, sin contar con inserción institucional ni formación específica, fueron figuras aisladas, con recorridos diferentes, pero que contaron con un importante capital simbólico y ocuparon lugares centrales en la vida política y cultural territoriana; Lynch Arribálzaga y Lestani se apoyaron en la institución municipal de Resistencia; Alumni contó con el respaldo de la Iglesia y luego también del gobierno bajo el peronismo.

Las distintas perspectivas que se trazaron entonces -la correntina, la inmigratoria y la católica- buscaron en el pasado líneas de acción que se proyectaban al presente, insertaban al Chaco en el devenir de la nación -sin conflictos con la historia nacional- y legitimaban a determinados grupos que buscaban constituirse en la dirigencia de la futura provincia. Cada una fijó sus particulares lugares de memoria: conmemoraciones, sitios históricos y pugnó por imponerse en la memoria colectiva chaqueña, para lo que entraron en polémicas que no llegaron a cerrar e interpelarían a los nuevos historiadores profesionales de la Universidad. 


\section{Referencias bibliográficas}

Alumni, J. (1948). Nuestra Señora de los Dolores y Santiago de La Cangayé. Apuntes históricos. Resistencia, Argentina: Moro.

Alumni, J. (1951). El Chaco. Figuras y hechos de su pasado. Resistencia: Moro.

Benedetti, A. (2009). Los usos de la categoría región en el pensamiento geográfico argentino. Scripta Nova. Revista Electrónica de Geografía y Ciencias sociales, 286. Recuperado de: http://www.ub.es/geocrit/ sn/sn-286.htm

Cattaruzza, A. (2003). Por una historia de la historia. En: Cattaruzza, A. y Eujanián, A. Politicas de la historia. Argentina 1860-1960. Buenos Aires, Argentina: Alianza.

Dávilo, B. y Gotta C. (comp) (2000). Narrativas del desierto, geografías de la alteridad. Rosario, Argentina: UNR.

Forcadell Álvarez, C. M. y Cruz Romeo, M (Ed). (2006). Provincia y nación. Los territorios del liberalismo. Zaragoza, España: Institución «Fernando el Católico» (C.S.I.C.) Excma. Diputación de Zaragoza.

Foster, R. (1939). Contribución a la historia del Chaco (Exploración de 1875-1876 y fundación de Resistencia. Rosario, Argentina: s/e.

Geraldi, S. (1965). Lo que me contaron mis abuelos o páginas históricas del Chaco, Resistencia, Argentina: edición del autor.

Gómez, H. (1939). Historia de la Gobernación del Chaco. Buenos Aires, Argentina: s/e.

Jacquet, H. (1996). Haciendo Historia en la aldea. Posadas, Argentina: edición del autor.

Laguarda, P. y Fiorucci, F. (eds.) (2012). Intelectuales, cultura y política en espacios regionales de Argentina (siglo XX). Rosario, Argentina: Prohistoria-EdUNLPam.

Leoni, M. S. (2015). Elites culturales y construcción de la región en el nordeste argentino en el siglo XX. Coordenadas, 2.

Lois, C. (1999). La invención del desierto chaqueño. Una aproximación a las formas de apropiación simbólica de los territorios del Chaco en los tiempos de formación y consolidación del estado nación argentino. Scripta Nova. Revista Electrónica de Geografía y Ciencias sociales, 38. Recuperado de http://www.ub.edu/geocrit/sn-38.htm 
Lois, C. y Troncoso, C. (1998). Integración y desintegración indígena en el Chaco: los debates en la Sociedad Geográfica Argentina (18811890). En: $1^{0}$ Congreso Virtual de Antropología y Arqueología. Ciberespacio, Recuperado de: www.naya.org.ar.

Lynch Arribálzaga, E. (1972). Fastos precursores e iniciales de la ciudad de Resistencia. Resistencia, Argentina: Región.

Lynch Arribálzaga, E. (1959). Materiales para una bibliografía del Chaco y Formosa. Resistencia, Argentina: Universidad Nacional del Nordeste

Martínez, A. T. (2013). Intelectuales de provincia: entre lo local y lo periférico. Prismas, Revista de historia intelectual, 17, pp.169-180.

Martínez, A. T. (2019). Discursos de identidad y geopolítica interior. Indios, gauchos, descamisados, intelectuales y brujos. Buenos Aires, Argentina: Biblos.

Masotta, C. (2001). Un desierto para la Nación. La Patagonia en las narraciones del estado de la Concordancia (1932-1943). En: Cuarto Congreso Chileno Antropología. Recuperado de: http:// rehue.csociales.uchile.cl

Micheletti, M.G. (2017). Las tensiones nación/provincia en la configuración de la historiografía argentina. La escritura de la historia en Santa Fe (1850-1950). Expediçoes: Teoria da História e Historiografia; 8, 83-114.

Philp, M. (comp.) (2011). Intervenciones sobre el pasado. Córdoba, Argentina: Alción.

Philp, M. (2013). Territorios de la historia, la politica y la memoria. Córdoba, Argentina: Alción.

Rusen, J. (1994). ¿Qué es la cultura histórica?: Reflexiones sobre una nueva manera de abordar la historia. Versión castellana inédita del texto original alemán. En K. Füssmann, H.T. Grütter y J. Rüsen. Keulen: Weimar y Wenen, Böhlau Historische Faszination. Geschichtskultur heute, 3-26. Traducción de F. Sánchez Costa e Ib Schumacher. Disponible en http://www.culturahistorica.es/ ruesen.castellano.html

Tissera, R. (1972). La invertebrada historia del Chaco. Región, 3 (20), 46-48

Venegas Delgado, H. (2012). La región en su perspectiva histórica. Estudios del Ishir, 2 (4), 3-26. 